\title{
A GESTÃO ESPORTIVA DE CATEGORIAS DE BASE DE BASQUETEBOL MASCULINO EM CLUBES DA CIDADE DE CAMPINAS - SP
}

Renato Schiavinato de Oliveira

Iara Cristina de Sousa Pereira

Marco Antonio Bettine de Almeida

\section{Resumo}

Observa-se na cidade de Campinas que, nos últimos cinco anos, as equipes masculinas adultas de basquetebol não participam dos campeonatos promovidos pela Federação Paulista de Basketball (FPB). Frente a este quadro pode-se deduzir que existam problemas na estrutura organizacional do basquetebol no caso destacado, focando-se a questão na formação inicial dos atletas. A partir disto, objetivamos no presente estudo de caso analisar o caráter da gestão das categorias de base masculinas da modalidade basquetebol em clubes da referida cidade, baseando-se no quadro sobre as características da Gestão Amadorista e Profissional desenvolvido por Melo Neto 1998, apud Azevedo, 2004). Após análise interpretativa das respostas obtidas, foi possível inferir que existe uma gestão hibrida nos clubes, tendendo à Amadorista.

\section{Palavras-Chave}

Basquetebol; Gestão esportiva; Categorias de base.

\section{THE SPORT MANAGEMENT IN CATEGORIES OF BASE FOR MALE BASKETBALL IN CLUBS OF CAMPINAS-SP.}

Renato Schiavinato de Oliveira

Iara Cristina de Sousa Pereira

Marco Antonio Bettine de Almeida

\begin{abstract}
It is observed in the city of Campinas that, in the last five years, the adult masculine teams of basketball do not participate of the championships promoted for the São Paulo Federacy of Basketball (FPB). Front to this picture can be deduced that problems in the organizational structure of the basketball in the detached case exist, focusing it question in the initial formation of the athletes. To leave of this, we objectify in the present study of case to analyze the character of the management of the masculine categories of base of the modality basketball in clubs of the related city, being based on the picture on the characteristics of the Amateur and Professional Management developed for Melo Neto 1998, apud Azevedo, 2004. After interpretative analysis of the gotten answers, was possible to infer that exists a hybrid management in the clubs, tending to the Amateur.
\end{abstract}

\section{Key-Words}

Basketball; Sport management; Categories of base. 


\section{INTRODUÇÃO}

$\mathrm{O}$ basquetebol configura-se numa modalidade desportiva que progressivamente vem ganhando espaço em território brasileiro, pois, segundo a Confederação Brasileira de Basketball (CBB), "o basquete esta cada vez mais difundido pelo pais" (CBB, 2007).

Apesar da grande propagação desta modalidade, observa-se na cidade de Campinas, a qual configura-se num dos pólos da região metropolitana de Sao Paulo, que nos últimos cinco anos somente o time da Ponte Preta, em 2006, disputou o Campeonato Paulista na Divisão Especial A1 da categoria adulta feminina, de acordo com o site da Federação Paulista de Basketball (FPB, 2007). Já na categoria adulta masculina, os times campineiros, de 2003 ate o presente ano, não disputaram nenhum campeonato a âmbito estadual promovido pela FPB.

Diante deste quadro, pode-se inferir que existam problemas na estrutura organizacional do basquetebol da cidade de Campinas-SP, e um destes pode situar-se na formação inicial dos atletas, focando-se principalmente na gestão das categorias de base dos clubes; tal fato e reiterado por Filin; Volkov, quando afirmam que:

Com base em nossa experiência, aconselhamos aos outros países que voltem a sua aten9ao para as equipes de base, pois aqui encontra-se o segredo do sucesso. As sele9oes adultas, nada mais são do que conseqüências dos trabalhos realizados anteriormente. (FILIN; VOLKOV, 1998 apud SANTANA, 2005, p. 191).

Isto posto, decidimos realizar um estudo que se constitui numa pesquisa de campo, entrevistando gestores de tres clubes renomados da cidade de Campinas-SP. Tais gestores são responsáveis pelas categorias de base do basquetebol masculino dos respectivos clubes em que atuam e, a partir das entrevistas, buscamos definir de qual tipo de Gestão se aproximam - se da Amadora ou Profissional - de acordo com quadro comparativo elaborado por( MELO NETO, 1998 apud AZEVEDO, 2007).

Desta forma, este trabalho visa contribuir para a discussão sobre a influencia da gestão das categorias de base do basquetebol como ponto de partida para a obtenção de um melhor resultado nas categorias seguintes. Esta discussão e pertinente para os profissionais da área de Educacao Física, constituindo-se num ponto de partida para uma visão mais abrangente sobre o assunto. 


\section{DISCUSSÃO TEÓRICA}

Segundo Azevedo (2004), a administração consiste em "planejár, organizar, dirigir e controlar as atividades de outras pessoas, ou subordinados, para atingir ou ultrapassar objetivos definidos". Já Capinussu, 1979 apud Azevedo, 2004, conceitua administração como uma tarefa que possibilita alcançar os objetivos previamente definidos com maior eficiência, ou seja, com menor dificuldade e maior rapidez.

De acordo com Melo Neto, 1998, apud Azevedo, 2004, podemos classificar a gestão em dois tipos, gestão Amadorista e Profissional, as quais possuem características distintas.

$\mathrm{Na}$ gestão Amadorista predomina o interesse de um grupo sobre os da totalidade; a visão dos componentes do grupo interno como principal publico-alvo; ênfase no fortalecimento interno do "grupo"; a direção não e remunerada ou a remuneração não e compatível com a competência profissional exigida e, portanto, não centrada em resultados; estrutura departamentalizada por funções tradicionais, voltadas para o gerenciamento das atividades; ênfase no "estatuto" como fonte de decisão no processo de gestão; alto poder de influência dos "conselheiros" que representam a forca de decisão; vigência do paradigma da "entidade sem fins lucrativos"; estreita vinculação com os "componentes do grupo" e a administração voltada para dentro.

Já na gestão Profissional, o predomínio e da visão estratégica, da busca de resultados; visão dos receptores dos serviços como segmentos de mercado; ênfase na busca de parceiros e investidores; a direção e remunerada e, normalmente, bem remunerada, portanto, cobrada em termos de resultados; estrutura divisional/ corporativa voltada para o gerenciamento das diversas atividades institucionais; ênfase na elaboração e implantação de "novos projetos de detecção de necessidades" como fonte de decisão no processo de gestão; alto poder de influência dos "gerentes profissionais" que representam a forca do conhecimento e a profissionalização; vigência do paradigma da "busca de resultados"; estreita vinculação com o "mercado" e a administração "voltada para fora".

Diante do exposto anteriormente, no tocante a gestão das categorias de base do basquetebol masculino, acreditamos que este caso especifico abarca certas questões que merecem destaque diante de sua importância, já que as categorias de base constituem- se numa fundamental etapa da iniciação esportiva, como já anteriormente citado, de acordo com FILIN; VOLKOV (1998, apud SANTANA, 2005, p.191). 
Segundo Beneli (2007), existem sete categorias no basquetebol masculino no Estado de Sao Paulo, que antecede a categoria adulta ou principal, e utilizam como critério para esta divisão a idade cronológica, sendo elas, Pre-mini (12 anos), Mini (13 anos), Mirim (14 anos), Infantil (15 anos), Infanto-juvenil (16 anos), Cadete (17 anos) e Juvenil (18 e 19 anos). O termo "categorias de base" e também utilizado pela Federação Paulista de Basquetebol (FPB) e pelas Associações Regionais de Basquetebol (ARB), entidades responsáveis pelo basquetebol no Estado de São Paulo, referindo-se a fase ou etapa cronológica em que estes atletas encontram-se, em oposição a categoria principal, ou seja, todas as categorias anteriores a categoria adulta.

Assim, a gestão das categorias de base do basquetebol masculino visa a formação inicial de atletas e o descobrimento de novos talentos, mas não somente isto: esta primeira formação no esporte, alem de promover atletas de alto nível de rendimento, também fomenta e dissemina a pratica do basquetebol, seja de maneira direta ou indireta. Isto porque, segundo Leoncini e Silva (2005), a gestão também pode ter como objetivo difundir o esporte em questão a fim de incrementar o mercado consumidor, ou seja, aumentar o numero de torcedores a partir da popularização de sua pratica, os quais irão consumir os produtos oriundos deste esporte, tais como uniformes dos times, equipamentos e acessórios ligados a modalidade, ingressos para os jogos, dentre outros.

(...) o surgimento do mercado consumidor de espetáculos esportivos não e um evento histórico, mas um processo mais ligado a popularização de sua pratica, conforme Bourdieu (1983). A popularização da prática cria as bases para a consolidação da industria do espetáculo. (LEONCINI; SILVA, 2005).

Neste contexto, cremos que a gestão das categorias de base da modalidade basquetebol carece de uma analise mais aprofundada sobre o que vem sendo realizado e perspectivado, já que dependendo do objetivo priorizado pelo clube, podem-se esperar distintas conseqüências para o desenvolvimento do esporte.

\section{OBJETIVOS}

Por intermédio da analise interpretativa das respostas fornecidas pelos gestores de categorias de base masculinas do basquetebol de clubes de Campinas-SP, objetivamos responder a seguinte questão, baseando-se no quadro desenvolvido por Melo Neto 1998 apud Azevedo, 2004): a atual gestão das categorias de base da modalidade basquetebol em clubes da cidade de Campinas-SP se aproxima de qual modelo, da gestão Amadorista ou Profissional? 


\section{METODOLOGIA}

O presente trabalho caracteriza-se por ser um estudo de caso, o qual "consiste no estudo de determinados indivíduos, profissões, condições, instituições, grupos ou comunidades, com a finalidade de obter generalizações". (LAKATOS, 1991, p.108).

Esta pesquisa foi realizada com gestores de três renomados clubes da cidade de Campinas-SP, sendo um de cada referida instituição. Segue os clubes os quais os respectivos gestores foram entrevistados: Sociedade Hípica de Campinas; Clube Campineiro de Regatas e Natação Tênis Clube de Campinas.

Ainda segundo Lakatos (1991), este trabalho utiliza-se da técnica de observação direta extensiva, baseando-se em formulário, o qual e definido como sendo um "roteiro de perguntas enunciadas pelo entrevistador e preenchidas por ele com as respostas do pesquisado".

O formulário por nos elaborado e dividido em duas partes, sendo que a primeira contem perguntas de cunho pessoal, como Nome, Idade, Clube em que atua, Cargo exercido no clube e Formação Profissional, e a segunda parte possui um total de sete perguntas baseadas no quadro comparativo de Melo Neto 1998 apud Azevedo, 2007 sobre as características Gestão Amadorista e Profissional. As perguntas da segunda parte do formulário são listadas a seguir:

1) Qual e o principal objetivo da gestão na categoria de base de basquetebol no clube em que o senhor atua?

2) A gestão das categorias de base do basquetebol no clube em que o senhor atua se estrutura de forma departamentalizada ou divisional/corporativa?

3) O senhor e contratado exclusivamente como gestor das categorias de base do basquetebol ou desempenha outros papeis na administração do clube?

4) Qual o público-alvo das categorias de base do basquetebol e como o gestor pretende atingir este publico?

5) Qual a ênfase dada por esta gestão no tocante a parceiros e investidores extemos para as categorias de base do basquetebol? 
6) $\mathrm{O}$ associado do clube em que o senhor atua tem algum tipo de participação nas decisões que englobam a gestão das categorias de base do basquetebol?

7) Qual e a influencia do estatuto do clube nas tomadas de decisão na gestão das categorias de base do basquetebol?

Os formulários foram aplicados em entrevistas fechadas, conforme anteriormente descrito. Foi realizada também uma discussão teórica dos temas pertinentes, além de uma análise de dados interpretativa das respostas obtidas. Esta analise e definida por Lakatos (1991) como a associação de idéias expressas pelo autor com outras de conhecimento do estudante, fazendo com que este realize uma apreciação pessoal e mesmo uma emissão de juízo sobre as idéias expostas. Tais resultados podem ser verificados no item seguinte.

\section{APRESENTAÇÃO E DISCUSSÃO DOS RESULTADOS}

A primeira entrevista realizada foi com o técnico de basquetebol do Tênis Clube de Campinas, de 43 anos, graduado em Educação Física e com pós-graduação em Treinamento Desportivo. O entrevistado, apesar de ser o gestor responsável pelas categorias de base do basquetebol no clube em que atua, não possui formação, especialização ou cursos em administração esportiva. A segunda entrevista foi-nos concedida pelo Coordenador Geral de Esportes do Clube Campineiro de Regatas e Natação, de 59 anos, e também graduado em Educacao Física. Ele e responsável por toda a gestão no tocante a modalidade basquetebol no clube em que atua, e, da mesma forma, não possui formação, especialização ou cursos em administração esportiva. A terceira e ultima entrevista foi feita com o Coordenador de Esportes da Sociedade Hípica de Campinas, de 39 anos, licenciado em Educacao Física.

Sobre a primeira pergunta, "qual e o principal objetivo da gestão na categoria de base de basquetebol no clube em que o senhor atua?", todos responderam que visam a "promoção e desenvolvimento desta prática esportiva". O primeiro e o segundo entrevistados citaram ainda que objetivam a "socialização entre os praticantes, alem do aprendizado dos fundamentos do esporte". $O$ coordenador geral de esportes do Clube Campineiro de Regatas e Natação enfatizou a "inclusão social". O terceiro, com outras palavras, afirma buscar "objetivos educacionais" nas categorias de base.

$\mathrm{Na}$ segunda questão, "a gestão das categorias de base do basquetebol no clube em que o senhor atua se estrutura de forma departamentalizada ou divisional/corporativa?", a resposta foi unânime: os três 
clubes tem gestão departamentalizada. Esta e uma clara característica da gestão clubistica ou amadorista. $\mathrm{Na}$ terceira questão, "o senhor e contratado exclusivamente como gestor das categorias de base do basquetebol ou desempenha outros papeis na administração do clube?", obtivemos a mesma resposta de todos os três entrevistados: eles desempenham outras funções dentro do clube. Esta falta de especificação de função também caracteriza uma gestão clubística ou amadorista.

$\mathrm{Na}$ quarta questão, sobre qual seria o publico alvo das categorias de base do basquetebol e como o gestor pretendia atingir este publico, todos os gestores responderam que "o publico alvo sao os associados". Há, no Tênis Clube de Campinas e no Clube Campineiro de Regatas e Natação, conforme foi-nos dito pelos entrevistados, as chamadas "peneiras", a fim de selecionar garotos que tenham a habilidade ou o talento necessário para jogar pelos times do clube como militantes. Segundo o técnico de basquetebol do Tenis Clube de Campinas, existia, por exemplo, um artigo no estatuto do clube que afirmava o seguinte: o militante, por ser não associado, podia constituir no maximo $30 \%$ do quadro de atletas da categoria de base do clube. No entanto, isto não ficava tão claro, dando margem a uma interpretação ambígua: no caso, ou cada time de uma determinada categoria de base pode ter no máximo $30 \%$ de militantes, ou no total de atletas das categorias de base devia haver apenas $30 \%$ de jogadores não-associados.

Na quinta questão, concemente a ênfase dada pela gestão quanta a parceiros e investidores externos para as categorias de base do basquetebol, todos os gestores responderam que os clubes são financeiramente auto-suficientes, mesmo porque as categorias de base são gerenciadas com as mensalidades pagas pelos associados do clube e das modalidades. Porem, nem por isso eles dispensam a parceria externa, pelo contrario: todos os clubes buscam investimentos externos e apoio de empresas que queiram patrocinar os times para viabilizar os seus projetos, no entanto, não e nada fácil conseguir um patrocinador. O que acontece muito são patrocínios esporádicos, sazonais, específicos para um ou outro evento promovido pelo clube, mas isto não acontece com freqüência; eles ate conseguem um ou outro investimento externo, mas esta e uma reclamação constante dos três gestores entrevistados. Segundo o quadro de Melo Neto, 1998 apud Azevedo, 2007, o qual tomamos por base para o presente trabalho, a ênfase na busca de parceiros e investidores e uma característica fundamental da gestão profissional.

Quanta a sexta pergunta, se o associado do clube teria algum tipo de participação nas decisões que englobam a gestão das categorias de base do basquetebol, a resposta dos três gestores entrevistados foi igual: esta participação se da de "forma indireta ", atraves de reuniões com os pais dos atletas, já que os 
jogadores são crianças e pré-adolescentes. Ou seja, o associado tem liberdade para fazer reclamações, questionamentos, dar sugestões, apresentar projetos, criticas, mas esta intervenção e limitada, pois as decisões são totalmente aprovadas pelo gestor responsável pelas categorias de base do clube. Tal estrutura também reflete uma gestão profissional, segundo as características apontadas no quadro de Melo Neto, 1998, apud Azevedo, 2007).

A sétima e ultima pergunta da entrevista referia-se a influência do estatuto do clube na tomadas de decisão na gestão das categorias de base do basquetebol. O primeiro entrevistado, do Tênis Clube de Campinas, afirmou que "pelo estatuto, o clube precisa ter no mínimo três modalidades competitivas, que no caso do Tênis Clube são tênis, basquete e natação ", no entanto, "nas categorias de base, não existe influencia". Já o segundo entrevistado, Coordenador Geral de Esportes do Clube Campineiro de Regatas e Natação, disse que "o estatuto do clube não fala nada sobre as categorias, só fala que se deve atender ao filho do sócio, pois se o clube investir no infanto-juvenil, o associado será fiel e manterá seu titulo em dia". O terceiro gestor, do clube Sociedade Hípica de Campinas, afirmou que o estatuto do clube influencia "principalmente na admissão dos não associados (sócios militantes) ".Sobre os sócios militantes, o gestor entrevistado do Tênis Clube de Campinas disse-nos que "hoje, e livre a participação tanto de militantes como de associados". Já o segundo entrevistado, do Clube Campineiro de Regatas e Natação, como já explicitado anteriormente, afirmou que no inicio do ano o clube promove "peneiras", principalmente com garotos menos favorecidos financeiramente, em sua maioria da periferia da cidade de Campinas, com o intuito de recrutar para o clube os sócios militantes, que apresentam aptidão para o basquetebol. Para tanto, o gestor diz utilizar-se da estratégia de divulgar macicamente atraves de cartazes nas escolas a data em que serão realizados os testes da "peneira", que ocorrem durante o mês de Janeiro, ferias escolares dos garotos. A visão estratégica e uma forte característica da gestão profissional.

Enfim, os entrevistados responderam de forma objetiva as questões propostas no formulário da entrevista por nos elaborado, e apresentou-nos dados e respostas que divergem entre si na classificação do clube em uma gestão "puramente" de cunho amadorista ou profissional. Especificamente com base nos resultados obtidos atraves da analise interpretativa das respostas fornecidas pelos gestores das categorias de base do basquetebol, podemos elaborar o seguinte quadro, no qual: A -Tênis Clube de Campinas; B - Clube Campineiro de Regatas e Natação e C -Sociedade Hípica de Campinas. 


\begin{tabular}{|c|c|c|c|}
\hline Questoes & Entrevistados & Amadorista & Profissional \\
\hline \multirow[t]{3}{*}{$\overline{1}$} & $\mathbf{A}$ & & $\mathbf{X}$ \\
\hline & B & $\mathbf{X}$ & \\
\hline & $\mathbf{C}$ & $\mathbf{X}$ & \\
\hline \multirow[t]{3}{*}{2} & $\mathbf{A}$ & $\mathbf{X}$ & \\
\hline & B & $\mathbf{X}$ & \\
\hline & C & $\mathbf{X}$ & \\
\hline \multirow[t]{3}{*}{3} & $\mathbf{A}$ & $\mathbf{X}$ & \\
\hline & B & $\mathbf{x}$ & \\
\hline & C & $\mathbf{X}$ & \\
\hline \multirow[t]{3}{*}{4} & $\mathbf{A}$ & $\mathbf{X}$ & \\
\hline & B & $\mathbf{X}$ & \\
\hline & $\mathbf{C}$ & $\mathbf{X}$ & \\
\hline \multirow[t]{3}{*}{5} & $\mathbf{A}$ & & $\mathbf{X}$ \\
\hline & B & & $\mathbf{X}$ \\
\hline & $\mathbf{C}$ & & $\mathbf{X}$ \\
\hline \multirow[t]{3}{*}{6} & $\mathbf{A}$ & & $\mathbf{X}$ \\
\hline & B & & $\mathbf{X}$ \\
\hline & $\mathbf{C}$ & & $\mathbf{X}$ \\
\hline \multirow[t]{3}{*}{7} & $\mathbf{A}$ & & $\mathbf{X}$ \\
\hline & B & $\mathbf{X}$ & \\
\hline & $\mathrm{C}$ & $\mathbf{X}$ & \\
\hline
\end{tabular}

\section{CONSIDERAÇÕES FINAIS}

A partir dos resultados obtidos, e possível inferir que, no caso analisado, não existe uma gestão puramente Amadorista ou Profissional; de acordo com o que pudemos observar a partir dos dados levantados, ha concretamente uma "gestão hibrida" que abarca aspectos de ambas as gestões.

Porem, pudemos observar, a partir das respostas concedidas pelos gestores entrevistados, que a gestão das categorias de base do basquetebol masculino em clubes de Campinas tende ao modelo Clubístico ou Amadorista, pois num total de vinte e uma respostas fornecidas, constatamos que treze respostas (62\%) aproximam-se do Modelo Amadorista de Gestão, enquanto que oito respostas (38\%) aproximam-se do Modelo Profissional. 


\section{REFERÊNCIAS}

CONFEDERAÇÂO Brasileira de basketball. Disponível em <http://www.cbb.com.br>. Acesso em 14 out. 2007.

NATIONAL Basketball Association. Disponível em: <http://www.nba.com>. Acesso em 14 out. 2007.

PREFEITURA Municipal de Campinas. Disponível em <http://www.campinas.sp.gov.br $>$. Acesso em 14 nov. 2007.

FEDERAÇÃO Paulista de Basketball. Disponível em <http://www.fpb.com.br>. Acesso em 14 nov. 2007.

BENELI, L. M. Basquetebol masculino paulista: apropriação das características do esporte profissional na estrutura organizacional das categorias de base. 2007. Dissertação (Mestrado) - Faculdade de Educacao Física, Universidade Estadual de Campinas, Campinas, SP. 2007.

LAKTOS, E. M.; MARCONI, M. A. Fundamentos de metodologia cientifica. 3. ed. São Paulo: Atlas, 1991.

GALATTI, L. R. Pedagogia do esporte: discutindo o processo de ensino - aprendizagem na modalidade basquetebol. Monografia (Trabalho de Conclusão de Curso) - Faculdade de Educacao Física, Universidade Estadual de Campinas, Campinas, 2002.

LEONCINI, M. P.; SILVA, M. T. Entendendo o futebol como um negocio: um estudo exploratório. Gest. Prod., São Carlos, v. 12, n.1, jan./abr. 2005.

AZEVEDO, P. H.; BARROS, J. F. A necessidade de administração profissional do esporte brasileiro e o perfil do gestor publico, em nivel federal, que atuou de 1995 a 2002. Rev. Digital EFDeportes, Buenos Aires, ano 10, n. 74, 2004.

SANTANA, W. C. Pedagogia do esporte na infância e complexidade. In: PAES, R. R. ; BALBINO, H. F. Pedagogia do esporte: contextos e perspectivas. PAES, R. R. e BALBINO, H. F. Rio de Janeiro: Guanabara, Koogan, 2005. 


\section{Renato Schiavinato de Oliveira, Faculdade de Educacao Física/Unicamp}

\section{lara Cristina de Sousa \\ Faculdade de Educacao Física /Unicamp}

\section{Marco Antonio Bettine de Almeida}

Faculdade de Educação Física/Unicamp

\section{Referência do artigo:}

\section{ABNT}

OLIVEIRA, R. S. A gestão esportiva de categorias de base de basquetebol masculino em clubes da cidade de Campinas - SP, v. 6, p. 609-619, 2008.

\section{APA}

Oliveira, R. S., Sousa, I. C., \& Almeida, M. A. B. (2008) A gestão esportiva de categorias de base de basquetebol masculino em clubes da cidade de Campinas - SP. Conexões, 6, 609-619.

\section{VANCOUVER}

Oliveira RS, Sousa IC, Almeida MAB. A gestão esportiva de categorias de base de basquetebol masculino em clubes da cidade de Campinas - SP. Conexões, 2008; 6: 609-619. 